OPEN ACCESS

Edited by:

Wei Cong,

Shandong University, China

Reviewed by:

Majid Pirestani,

Tarbiat Modares University, Iran

Jinshan Xu,

Chongqing Normal University, China

Maria Anete Lallo,

Paulista University, Brazil

${ }^{*}$ Correspondence:

Jialing Bao

baoj|swu.edu.cn

Zeyang Zhou

zyzhou@swu.edu.cn

Specialty section:

This article was submitted to

Clinical Microbiology,

a section of the journal

Frontiers in Cellular and

Infection Microbiology

Received: 14 April 2021

Accepted: 04 May 2021

Published: 21 May 2021

Citation:

Bao J, Mo B, An G, Luo J, Poncz M, Pan G, Li T and Zhou Z (2021) Von

Willebrand Factor Facilitates

Intravascular Dissemination of Microsporidia Encephalitozoon hellem. Front. Cell. Infect. Microbiol. 11:694957. doi: 10.3389/fcimb.2021.694957

\section{Von Willebrand Factor Facilitates Intravascular Dissemination of Microsporidia Encephalitozoon hellem}

\author{
Jialing Bao ${ }^{1,2 *}$, Biying Mo ${ }^{1,2}$, Guozhen An ${ }^{1,2}$, Jian Luo ${ }^{1,2}$, Mortimer Poncz ${ }^{3}$, \\ Guoqing Pan ${ }^{1,2}$, Tian $\mathrm{Li}^{1,2}$ and Zeyang Zhou ${ }^{1,2,4^{*}}$ \\ ${ }^{1}$ State Key Laboratory of Silkworm Genome Biology, Southwest University, Chongqing, China, ${ }^{2}$ Chongqing Key Laboratory \\ of Microsporidia Infection and Control, Southwest University, Chongqing, China, ${ }^{3}$ Department of Pediatrics, The Perelman \\ School of Medicine, University of Pennsylvania, Philadelphia, PA, United States, ${ }^{4}$ College of Life Sciences, Chongqing \\ Normal University, Chongqing, China
}

Microsporidia are a group of spore-forming, fungus-related pathogens that can infect both invertebrates and vertebrates including humans. The primary infection site is usually digestive tract, but systemic infections occur as well and cause damages to organs such as lung, brain, and liver. The systemic spread of microsporidia may be intravascular, requiring attachment and colonization in the presence of shear stress. Von Willebrand Factor (WWF) is a large multimeric intravascular protein and the key attachment sites for platelets and coagulation factors. Here in this study, we investigated the interactions between WWF and microsporidia Encephalitozoon hellem (E. hellem), and the modulating effects on E. hellem after WWF binding. Microfluidic assays showed that E. hellem binds to ultra-large WWF strings under shear stress. In vitro germination assay and infection assay proved that $E$. hellem significantly increased the rates of germination and infection, and these effects would be reversed by WWF blocking antibody. Mass spectrometry analysis further revealed that WWF-incubation altered various aspects of E. hellem including metabolic activity, levels of structural molecules, and protein maturation. Our findings demonstrated that VWF can bind microsporidia in circulation, and modulate its pathogenicity, including promoting germination and infection rate. WWF facilitates microsporidia intravascular spreading and systemic infection.

Keywords: von Willebrand factor, Encephalitozoon hellem, microsporidia, intravascular dissemination, infection

\section{INTRODUCTION}

Microsporidia are a group of intracellular parasites that have recently been re-classified to fungi (Hirt et al., 1999; Han and Weiss, 2017). The host range of microsporidia is extremely wide, and at least 15 species are human pathogens with the major ones being Enterocytozoon bieneusi (E. bieneusi), Encephalitozoon hellem (E. hellem), Encephalitozoon cuniculi (E. cuniculi) and Encephalitozoon intestinalis (E. intestinalis) (Weiss, 2001; Valencakova and Danisova, 2019). Microsporidia extrude the polar tube inside-out to inject sporoplasm into the host cells. This 
process is called germination and is the key step for infection (Franzen, 2005). Inside the host cell, the sporoplasm proliferates and form more new spores that will further infect surrounding cells (Weber et al., 1993; Meissner et al., 2012). Microsporidia infections could be local and restrained, yet systemic even fatal infections are not rare (Weber et al., 1994; Weiss, 1995; Meissner et al., 2012). Microsporidia spores may disseminate systemically via intravascular system (Anderson et al., 2019; Han et al., 2019), however the mechanistic details of dissemination via circulatory system have not been fully examined.

In circulatory system, Von Willebrand factor (VWF) mediates the binding and activation of various cells and molecules such as platelets and factor VIII (Sadler, 1998; Yee et al., 2014; Lenting et al., 2015; Dong et al., 2019). Furthermore, the involvements of VWF in pathogen dissemination and inflammation have been reported in multiple settings. During acute infections, such as Escherichia coli infection may induce the haemolytic uremic syndrome, triggering the formation of microvascular thrombi mediated by Von Willebrand Factor (VWF) (Zheng and Sadler, 2008; Pillai et al., 2016; Ueda et al., 2017). Studies also revealed that $\mathrm{VWF}$ is able to directly bind to Staphylococcus aureus in blood under shear stress and promote intravascular infection of the sub-endothelium (Viela et al., 2019). VWF is also found to bind Streptococcus pneumonia, promoting pathogen aggregation and attachment to the endothelium surface (Jagau et al., 2019; Viela et al., 2019). In addition, malarial parasitemia caused by Plasmodium vivax also involves VWF binding and endothelial activation (Barber et al., 2015). Furthermore in chronic infection conditions, the endothelium damage and related plasma VWF levels increasement are reported. These conditions include carcinomas, chronic parasites infections and human immunodeficiency virus (HIV) infections (Park et al., 2012; van den Dries et al., 2015; Kong et al., 2020), and those individuals are susceptible groups of microsporidia infections.

VWF is a large multidomain protein. The type D domain (VWFD) in D'D3 assembly is not only essential for factor VIII binding but also crucial for multimerization of VWF (Dong et al., 2019). More importantly, VWFD domain is highly conserved in a lot of proteins such as vitellogenin and mucins, and these proteins have been reported to be mediators of pathogen invasion and dissemination in hosts (Sicard et al., 2017; Meng et al., 2018). Based on above facts, it is of great interest to investigate the essential role of VWF in mediating microsporidia dissemination and systemic infections via circulatory system.

Here in this study, we used the microsporidia E. hellem as a representative infection agent. We utilized various in vitro and in vivo methods to investigate the interactions between $E$. hellem and VWF. We proved that E. hellem spores could directly bind to VWF multimers under shear stress, and the D'D3 domain is essential for the direct interaction. Upon VWF binding, the germination and infection rates of E. hellem were significantly increased. Mass spectrometry analysis revealed various biological processes, such as metabolic activities, increased levels of structure molecule levels, and protein maturation of $E$. hellem were affected by VWF interaction. Together, our study is the first to describe key roles of VWF in microsporidia hematogenous dissemination.

\section{MATERIALS AND METHODS}

\section{VWF Proteins}

Native full-length human VWF, termed FL-VWF, was purchased from Abcam (ab88533, Abcam, USA). Recombinant VWF containing VWFD domain in the partial-length D'D3 assembly (S764-C1130, His-tagged), was expressed and purified from Rosetta (DE3) cells transformed with His-tagged pET32 plasmid (Novagen) containing the target sequence (Robertson et al., 2008). The partial length of D'D3 assembly excluded several cysteines that are essential for disulfide bonding, aiming for better solution of the expressed protein. Yet the recombinant protein was retained in the inclusion bodies thus dissolved in $8 \mathrm{M}$ Urea, $20 \mathrm{mM}$ Tris-Hcl, $0.5 \mathrm{M} \mathrm{NaCl}, 1 \mathrm{mM}$ DTT, $1 \mathrm{mM} 2-$ mercaptoethanol at $\mathrm{pH} 8.0$, and then filtered and loaded onto HiTrap $^{\text {TM }}$ chelating column (GE Healthcare Life Sciences, USA). Refolding of the bound proteins is achieved by very slowly $(0.1$ $\mathrm{ml} / \mathrm{min}$ ) wash the column with a liner $8-0 \mathrm{M}$ urea gradient, and then eluted by imidazole-containing elution buffer (Duan et al., 2006; Volonte et al., 2011).

\section{E. hellem Microsporidia}

E. hellem strain (ATCC 50504/50451) was a gift from Professor Louis Weiss (Albert Einstein College of Medicine, USA). Rabbit kidney cells (RK13, ATCC CCL-37) were cultured in 10\% fetal bovine serum (FBS, ThermoFisher) containing Minimum Essential Medium Eagle (MEM, Gibco) with penicillin (100 U/ $\mathrm{ml})$-streptomycin $(100 \mu \mathrm{g} / \mathrm{ml})$ at $5 \% \mathrm{CO}_{2}$. Confluent monolayers were infected with $E$. hellem. The spores were collected from culture media, purified by passing them through a $5 \mu \mathrm{m}$ size filter (Millipore=) to remove host cells, concentrated by centrifugation, and stored in sterile distilled water at $4^{\circ} \mathrm{C}$ (Visvesvara et al., 1991). Spores used in these experiments were counted with a hemocytometer (three times/sample) and averaged.

\section{Microfluidic Chamber VWF Binding Assay}

FL-VWF protein $(20 \mu \mathrm{g} / \mathrm{ml})$ was perfused through a flow chamber slide ( $\mu$-slide I luer, Cat\# 80176, Ibidi, Germany), with shear stress of $5 \mathrm{dyn} / \mathrm{cm}^{2}$ for $2 \mathrm{~min}$ with the same concentration of bovine serum albumin (BSA) (Sangon Biotech) used as a control. E. hellem spores $\left(10^{5} / \mathrm{ml}\right)$ were then perfused through the channel for $1 \mathrm{~min}$. The channels were washed with PBS, and then fixed with $4 \%$ paraformaldehyde. The VWF "strings" along the channel were visualized under a fluorescent microscope after incubation with anti-VWF IgG (ab6994, Abcam, USA) followed by Alexa 594-labeled secondary antibody. The E. hellem spores were visualized by Calcofluor-white (CFW) (Sigma-Aldrich), a specific dye for chitin on the microsporidia spore surface (Luna et al., 1995). 


\section{Recombinant VWF-D'D3 Assembly Binding to E. hellem Spore}

Recombinant VWF-D'D3 (partial length, containing VWFD) $(20 \mu \mathrm{g} / \mathrm{ml})$ was incubated with $E$. hellem spores $\left(10^{7} / \mathrm{ml}\right)$ for $30 \mathrm{~min}$, and then the spores were washed and fixed. The control group was incubated with the same concentration of EGFP (Enhanced Green Fluorescent Protein), also expressed, expressed and purified from EGFP-containing pET32 transformed DE3 cells. Direct interaction between VWF-D'D3 and E. hellem was observed by fluorescent microscope using antiVWF IgG (ab6994, Abcam) followed by Alexa 488-labeled secondary antibody, and DAPI (4',6-diamidino-2phenylindole) (Sigma-Aldrich), respectively.

To further investigate the binding specificity, microfluidic chamber assay was applied. FL-VWF protein $(20 \mu \mathrm{g} / \mathrm{ml})$ was perfused through a flow chamber slide ( $\mu$-slide I luer, Cat\# 80176, Ibidi, Germany), with shear stress of $5 \mathrm{dyn} / \mathrm{cm}^{2}$ for 2 min. Next, recombinant VWF-D'D3 (20 $\mu \mathrm{g} / \mathrm{ml})$ preincubated E. hellem spores $\left(10^{5} / \mathrm{ml}\right)$ or same concentration of EGFP protein pre-incubated E. hellem spores $\left(10^{5} / \mathrm{ml}\right)$ were perfused through the chamber for $1 \mathrm{~min}$. The channels were washed with PBS, and then fixed with $4 \%$ paraformaldehyde. The VWF "strings" along the channel were visualized under a fluorescent microscope after incubation with anti-VWF IgG (ab6994, Abcam, USA) followed by Alexa 594-labeled secondary antibody. The E. hellem spores were visualized by Calcofluor-white (CFW) (Sigma-Aldrich), and the recombinant VWF-D'D3 was visualized by anti-His antibody (SAB1305538, Sigma-Aldrich, Canada) followed by Alexa 488-labeled secondary antibody.

\section{E. hellem Germination and Infection}

Untreated or pre-incubated E. hellem spores were subjected to germination, triggered by germination buffer $(140 \mathrm{mM} \mathrm{NaCl}, 5$ $\left.\mathrm{mM} \mathrm{KCl}, 1 \mathrm{mM} \mathrm{CaCl}_{2}, 1 \mathrm{mM} \mathrm{MgCl}_{2}, \mathrm{pH} 9.5\right)$ at $37^{\circ} \mathrm{C}$ for $10 \mathrm{~min}$, and then $5 \%\left(\mathrm{v} / \mathrm{v}\right.$, final ratio) $\mathrm{H}_{2} \mathrm{O}_{2}$ (Sangon Biotech) was added for 5 min (Leitch et al., 1993; He et al., 1996; Pattana Jaroenlak et al., 2020).

For infection assay, human foreskin fibroblast cells (HFF, ATCC CRL-2522) were maintained in Dulbecco's Modified Eagle Medium (DMEM, ThermoFisher Scientific) with penicillinstreptomycin (ThermoFisher Scientific) supplemented with 10\% FBS (ThermoFisher Scientific) at $5 \% \mathrm{CO}_{2}$. The E. hellem spores were then added to HFF cells (20:1 spores/cells) and co-culture for various time periods. The infection rate of E. hellem was assessed by FISH (fluorescence in situ hybridization) assay, using Cy3-labeled oligonucleotide probes targeted to species-specific sequences of E. hellem $16 \mathrm{~S}$ rRNA (5'ACTCTCACACTCACTTCAG-3') to specifically label the proliferating $E$. hellem inside host cells. In brief, E. hellem infected HFF cells were fixed, then incubated with hybridization buffer ( $900 \mathrm{mM} \mathrm{NaCl}, 20 \mathrm{mM}$ Tris $\mathrm{pH} 7.5,0.01 \%$ SDS) at $46^{\circ} \mathrm{C}$ for $12 \mathrm{~h}$. Intracellular E. hellem in the host cells was visualized using fluorescently labeled probe (5 pM) under microscopy. The host cells were visualized by DAPI staining. The infection rate was calculated by the ratio of FISH-positive HFF cells over all cells in 20 randomly selected fields.

\section{Label-Free Quantitative Mass Spectrometry}

Freshly purified E. hellem spores $\left(10^{8} / \mathrm{ml}\right)$ were incubated with FL-VWF $(20 \mu \mathrm{g} / \mathrm{ml})$ for $30 \mathrm{~min}$. The spores were then washed with PBS. To extract the total protein, experimental and control spores not exposed to VWF were lysed with $1 \mathrm{ml}$ of SDT-lysis buffer (4\% SDS, $0.1 \mathrm{~mol} / \mathrm{l}$ dithiothreitol, and $0.1 \mathrm{~mol} / \mathrm{l}$ Tris $\mathrm{HCl}$, pH 7.6) with $10 \mu$ l Protease Inhibitor Cocktail (Sangon Biotech) using acid-washed glass beads (diameter: $425-600 \mu$, Sigma) in a Precellys-24 (Bertin Technologies). Triplicate protein samples were prepared from each experiment, and three experiments were performed. The samples were then subjected to label-free quantitative mass spectrometry.

\section{Statistics}

Results of the E. hellem germination and infection ratios were compared using paired Student's t-test. Statistical analysis of the mass spectrometry results were conducted using a one-way ANOVA followed by Bonferroni's post-hoc test was used to show significant differences in protein expression. Statistical significances were analyzed and represented with $\mathrm{F}$ values, degree of freedom, as well as with $\mathrm{P}$ values.

\section{RESULTS}

\section{E. hellem Binds to Ultra-Large VWF Under Shear Stress}

To investigate whether VWF is essential for hematogenous dissemination of microsporidia, FL-VWF was perfused with $E$. hellem spores through the microfluidic chamber under shear stress. After washing and fixation, VWF strings and E. hellem spores were visualized by fluorescent microscopy. As shown in Figures 1A,B, E. hellem spores specifically attached to the VWF oligomers under shear stress, while no binding to control protein BSA. Also, the shear stress is important for E. hellem binding on VWF, for VWF undergoes a conformational transition from a compacted, globular to an extended form (Vergauwe et al., 2014). The inference is proved in Figure 1C, showing that when no shear stress presents VWF clumped together and no E. hellem binding on it. These results further confirmed the importance of VWF mediating microsporidia dissemination under physiological conditions.

\section{The VWF-D'D3 Assembly Is Key Binding Region for E. hellem on VWF}

Next, we investigated whether the VWFD domain containing D'D3 assembly is key binding region for E. hellem. The purified recombinant VWF-D'D3 assembly (Figure 2A) was incubated with $E$. hellem spores, and the binding effect was proved by flow cytometry and fluorescent microscopy analysis (Figures 2B,C).

To further confirm the key role of D'D3 assembly in $E$. hellem-VWF binding, recombinant D'D3 assembly was applied to pre-incubate with E. hellem and then the spores were perfused with FL-VWF in microfluidic chamber under shear stress. As shown in Figure 3 that, D'D3 pre-incubation interferes with 
A
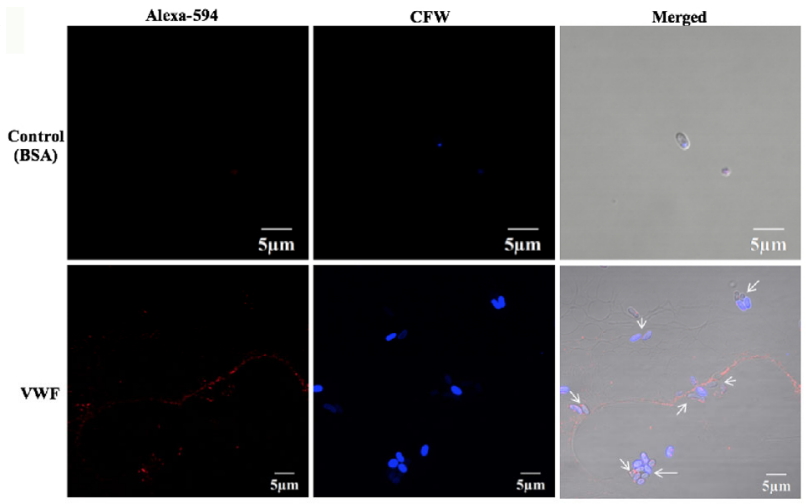

C
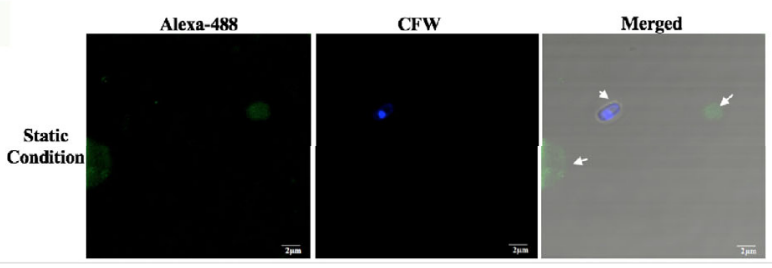

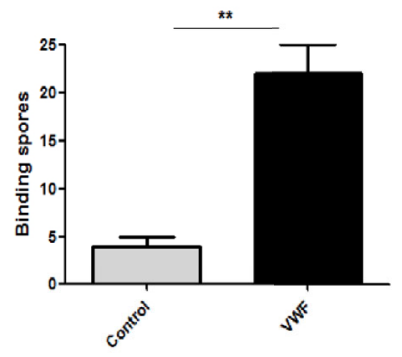

FIGURE 1 | E. hellem spores attach to FL-VWF under flow. (A) Representative images of control protein (BSA, top) or FL-WWF (bottom), both at 20 $\mu$ g/ml were perfused through the microfluidic chamber with $E$. hellem spores $\left(10^{5}\right.$ cells $\left./ \mathrm{ml}\right)$ under flow at $5 \mathrm{dyn} / \mathrm{cm}^{2}$, respectively. The channels were then washed, fixed and stained by Alexa-594-labeled anti-WWF antibody and calcofluor-white (CFW). The fluorescent microscopy analysis showed that the VWF formed ultra large multimers under flow (red), and E. hellem spores (blue) attached to the strings of ultra large WWF strings, as pointed out by white arrows in the right figures. (Scale bar $=5 \mu \mathrm{m})$. (B) The number of binding spores in the channels were calculated, based on three independent studies with 8 random fields for each study $\left(\mathrm{F}(1,23)=2.25,{ }^{* *} \mathrm{P}<0.01\right)$. (C) Under static conditions with no shear, the FL-WWF clumped and aggregated together (green). The E. hellem spores (blue) are not able to bind to clumped WWF.

E. hellem-VWF binding while pre-incubation with un-related protein EGFP had no interference effect. These results indicated that the binding site was pre-occupied by the assembly, and D'D3 assembly is the key binding region for E. hellem interaction on VWF.

\section{VWF Binding Promotes E. hellem Germination}

We next examined whether binding to VWF by microsporidia would influence the biology and potentially influence systemic infection by this organism. We first examined whether binding of spores to VWF influences germination. Freshly purified E. hellem spores $\left(10^{8} / \mathrm{ml}\right)$ were incubated with FL-VWF for $1 \mathrm{~h}$. Controls were either untreated $E$. hellem spores, spores incubated with VWF together with a blocking anti-human VWF antibody (Abcam, USA), or spores incubated with VWF together with an isotype antibody control. After incubation, E. hellem spores from each group were washed with PBS and then subjected to germination accordingly. Under fluorescent microscope, untreated E. hellem spores will show blue color due to DAPI staining of their nuclei; while germinated spore will show no color as the sporoplasms with their nuclei had already been extruded. The germination rate was then assessed by calculating the ratio of germinated spores over all spores under the view. Results showed that incubation of the spores with VWF significantly promoted E. hellem germination, and this effect was inhibited specifically by blocking anti-VWF antibody (Figure 4).

\section{VWF-Bound E. hellem Demonstrates Enhanced Host Cell Infectivity}

Another potential manner by which VWF may enhance systemic spread of microsporidia infection is by enhancing its ability to infect host cells. We examine this issue by pre-incubating $E$. hellem spores with FL-VWF, while the controls were either untreated E. hellem spores or spores treated with BSA. Another control was to pre-germinate the spores to enhance infectivity. The various pre-treated E. hellem spores were then co-cultured with HFF cells to allow infection, and then washed and fixed. The proliferating $E$. hellem inside the host cells were visualized by fluorescently labeled FISH probe. The infection rate was calculated by the ratio of FISH-positive HFF cells over total HFF cells. As shown in Figure 5, the infectivity of E. hellem was significantly increased after FL-VWF incubation, almost to the level of pre-germinated spores.

\section{Mass Spectrometry Analysis of the Impacts of VWF Binding on E. hellem}

Label-free quantitative mass spectrometry was utilized to analyze the E. hellem protein change after VWF incubation. Various 
A

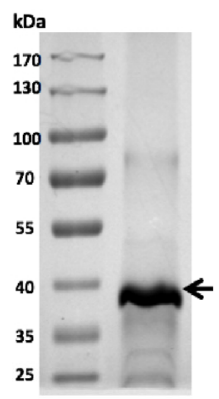

C
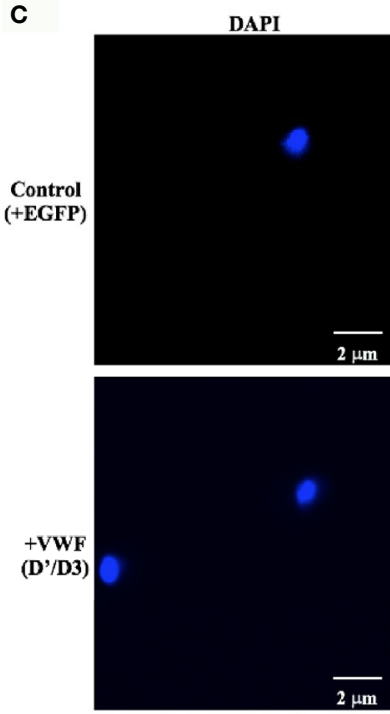

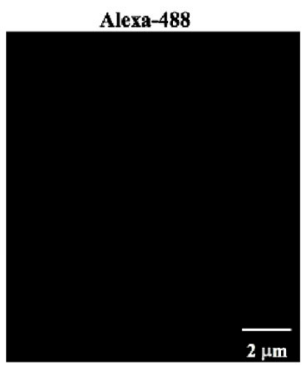

B
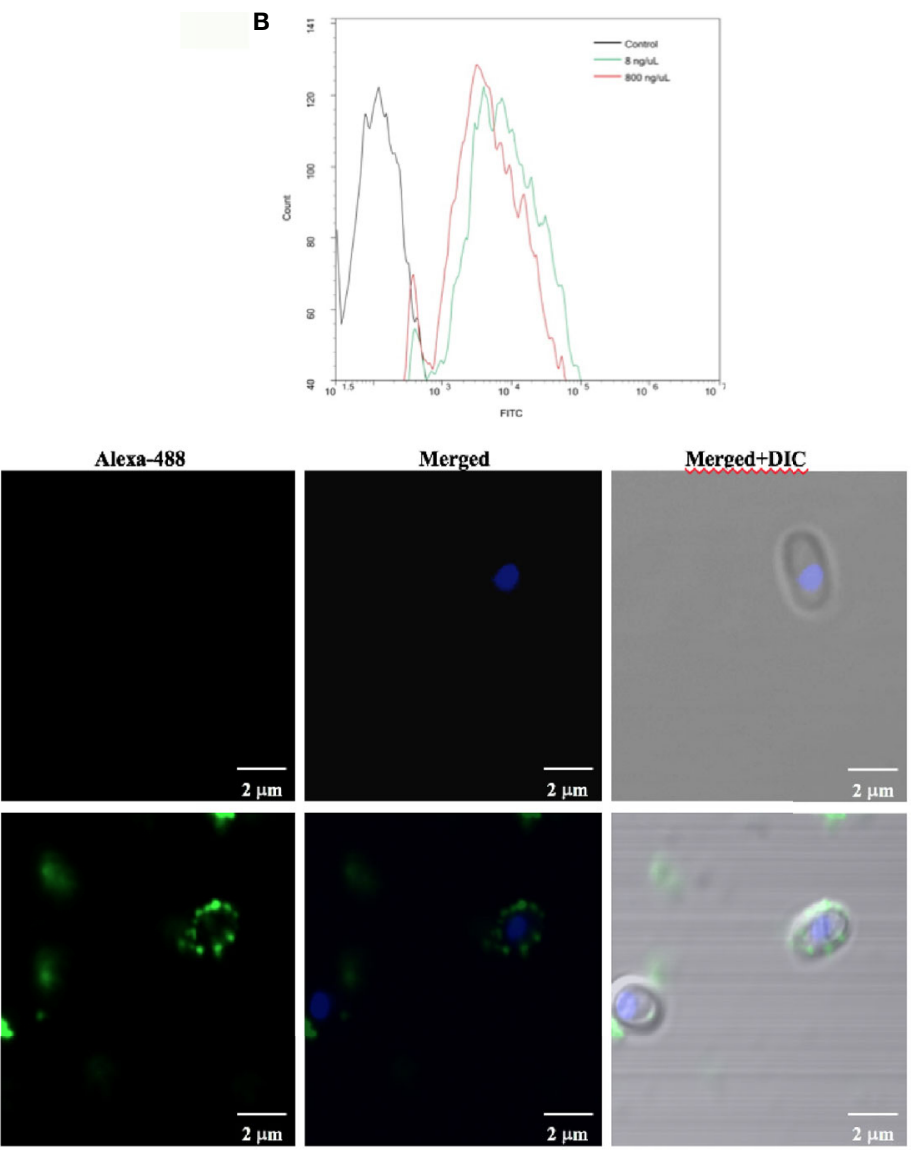

FIGURE 2 | WWF-D'D3 binds to E. hellem spores. (A) Coomassie staining of recombinant WWF-D'D3. Arrow shows the major protein size at the expected size 40 kDa. (B) Flow cytometry analysis of D'D3 binding to E. hellem. E. hellem spores $(1 \times 104$ cells) were incubated respectively with, isotype antibody control (in black line), $8 \mathrm{ng} / \mathrm{\mu l}$ recombinant WWF-D' D3 (in green line), and $800 \mathrm{ng} / \mathrm{\mu l}$ recombinant WWF-D'D3 (in red line). The result showed that with the increasing amount of recombinant WWF adding, the fluorescence signal increased as well. (C) Representative images of $E$. hellem spores were incubated with either control, recombinant EGFP (top) or WWF-D'D3 (bottom), both at $20 \mu \mathrm{g} / \mathrm{ml}$ for $30 \mathrm{~min}$, then the spores were washed by PBS. After fixation, the direct interaction between WWF (green) and E. hellem (blue) was observed by fluorescent microscope (Scale bar $=2 \mu \mathrm{m})$.

proteins were significantly increased, including ones involved in metabolic activities, DNA synthesis and intracellular transportation. Changes in the levels of specific proteins of either an increase or a decrease of two fold following FL-VWF binding are shown in Table 1. The differentially expressed proteins were further subjected to gene ontology (GO) annotation and enrichment analysis, as shown in Figure 6. Various aspects of E. hellem are altered after VWF binding, including biological process, molecular function and cellular compartment.

\section{DISCUSSION}

Current study is the first to show a direct interaction between plasma protein VWF and the microsporidia, E. hellem, and demonstrate that the binding of VWF to E. hellem spores significantly enhances their germination and infectivity abilities.
Mass spectrometry analysis revealed that various proteins expression levels of E. hellem were altered after VWF interaction. For instance, glucose-6-phosphate isomerase, an enzyme involved in glucose metabolism (Kugler and Lakomek, 2000); YOP1, a protein associated with vesicle-mediated transportation and invasion (Viljanen et al., 1991); and aminopeptidase, an enzyme associated with parasitophorous vacuole formation (Lu et al., 2020), were all up-regulated. In the meantime, the translation initiation factor $2 \mathrm{~B}$, DNA polymerase, and trehalase, a protease responsible for metabolic process in extreme condition (Zhao et al., 2016), were all significantly downregulated. These changes together indicate that binding by VWF signals E. hellem to slow-down regular DNA and protein synthesis, change the metabolism mode, accelerate vesicle transportation, and other modifications to prepare for germination by the pathogen and invasion of surrounding host cells.

VWF is an essential protein in coagulation and thrombosis, binding to platelet's glycoprotein Ib/IX receptor, to circulating 


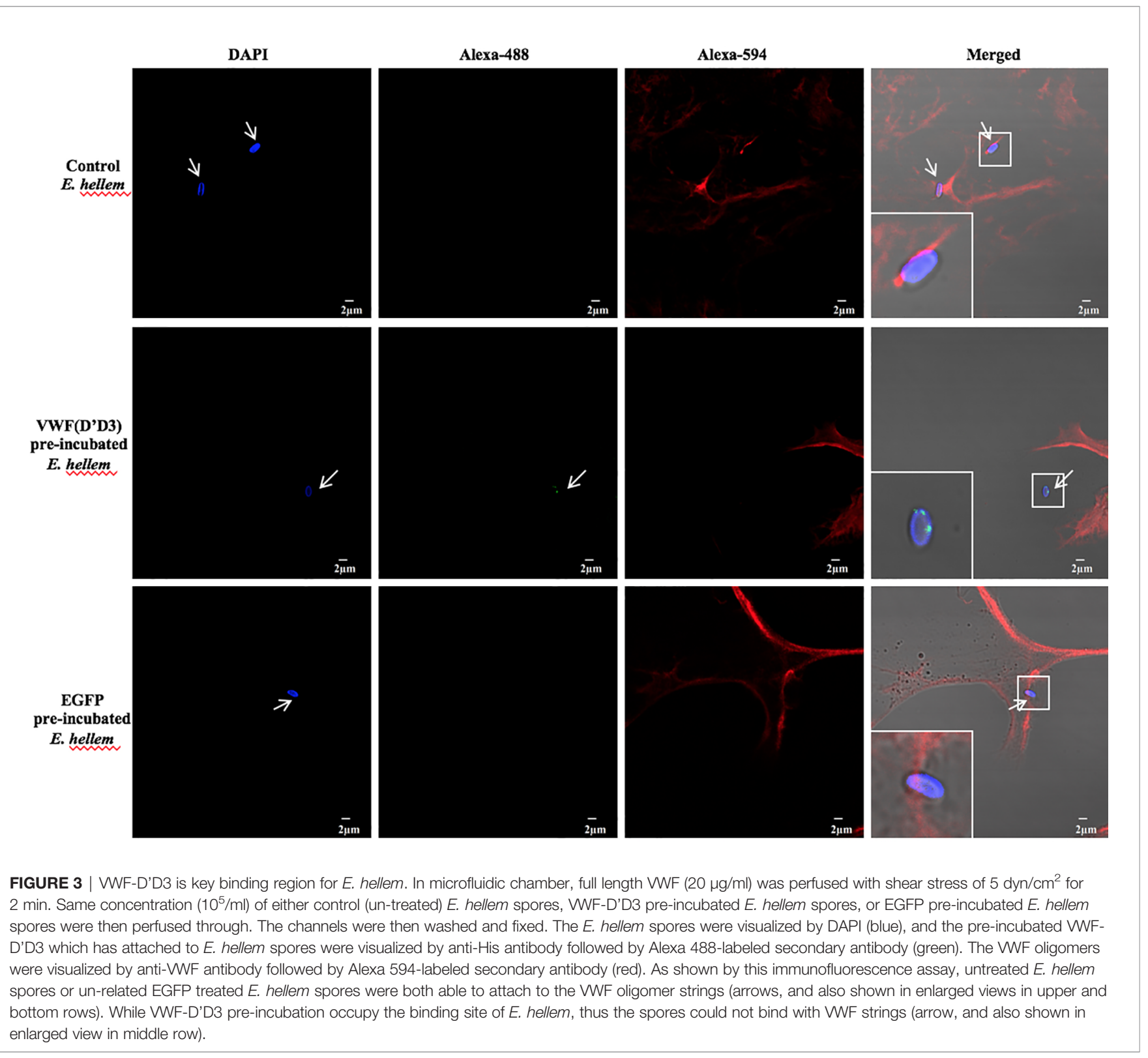

coagulation factor VIII and to exposed subendothelial collagen amongst other ligands (Sadler, 1998). It is known the D'D3 assembly of VWF is important for various ligands binding including coagulation factors FVIII, P-selectin and GpIba, and even some pathogens (Michaux et al., 2006; O'Seaghdha et al., 2006; Madabhushi et al., 2014; Yee et al., 2014). In particular, the D' region (composed of TIL' and E' domains) is especially important for FVIII binding (Shiltagh et al., 2014). Thus in this study, we constructed the recombinant VWF-D'D3 contains full of TIL', E' and most part of D3 (S764-C1130). We aimed to have a construct which retains the full binding abilities but without the residues such as C1142 and C1222 for inter-chain disulfide bonding, so that will get homogenous monomeric protein (Hilbert et al., 2003;
Shapiro et al., 2014; Lenting et al., 2015). With this protein, we managed to prove that D'D3 region is the key binding site for E. hellem on VWF, thus the occupation by E. hellem might interfere with physiologic functions of VWF and any related pathophysiologic processes. It would also be quite interesting to examine whether binding of microsporidia to the D'D3 region of VWF contributes to hemostatic conditions. A case study in a patient with acute myeloblastic leukemia who developed a systemic microsporidia infection also developed disseminate intravascular coagulopathy, consistent with VWF binding to microsporidia interfering with physiologic hemostatic (Yazar et al., 2003). Other reports also are consistent with systemic microsporidia effecting coagulation and thrombosis (Small et al., 2014; Bukreyeva et al., 2017; Pariyakanok et al., 2019). 
A

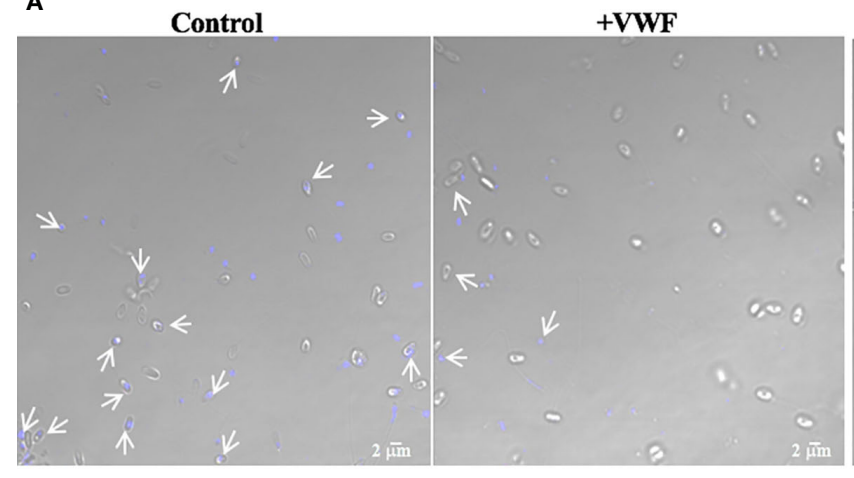

VWF+VWF-Antibody

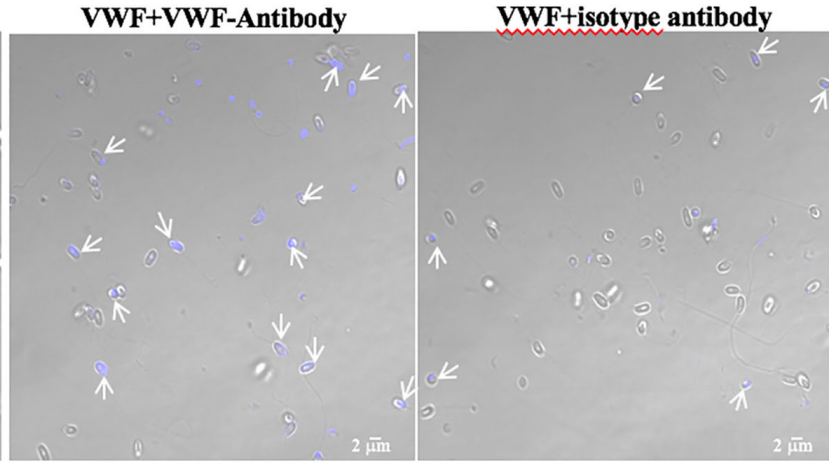

B

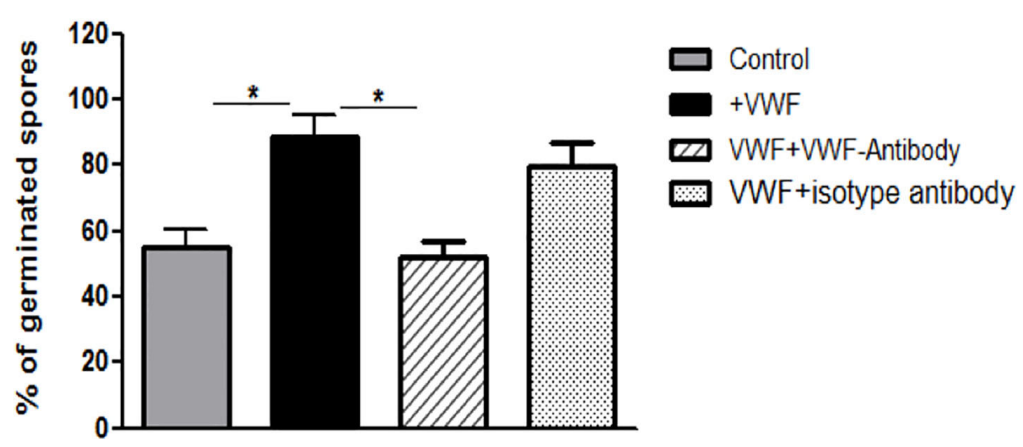

FIGURE 4 | WWF binding promotes E. hellem germination. (A) Representative images of E. hellem germination affected by WW. The control group E. hellem spores were untreated by any protien; The WWF group E. hellem spores were incubated with FL-WWF; The WW + WWF-antibody group E. hellem spores were treated by WW together with anti-WWF antibody; The WWF + isotype antibody group E. hellem spores were treated by WWF together with isotype antibody control. All the spores from each group were then stimulated with germination buffer to further trigger germination. The E. hellem spores were then stained by DAPI, and ungerminated spores will show blue color (pointed out by arrows). (Scale bar $=5 \mu \mathrm{m})$. (B) Germination rates were calculated by the ratio of germinated spores over all spores, based on three independent studies with 10 random fields per study. The results showed that WWF treatment significantly promoted E. hellem spores' germination $\left(F(1,29)=1.89,{ }^{*} P<0.05\right)$, and this effect was inhibited by WW specific antibody $\left(F(1,29)=2.09\right.$, $\left.{ }^{*} P<0.05\right)$.

Bacterial binding to VWF promotes bacterial settlement, and facilitates the pathogens transmigration and into deeper tissue sites (Steinert et al., 2020). We hypothesized that binding of microsporidia to VWF may also be the underlying mechanism of local and disseminated inflammations. On the other hand, we would not exclude the role of phagocytotic cells facilitating microsporidia spreading, as doing so to other pathogens (Guirado et al., 2013; Delgado Betancourt et al., 2019). However, our preliminary data showed that microsporidia interaction with phagocytes down-regulated the cells' maturation and proper functions such as migration abilities. Thus we hypothesized that microsporidia 'spreading' by the dysfunctional cells may not be as efficient as by shear stress in blood and by binding with VWF for better infection or transmigration to deeper tissues. Furthermore, considering the fact that VWF is a mediator for many other pathogens, such as $S$. aureus dissemination, it will be interesting and important to know whether the interaction with E. hellem interferes or facilitates co-infection with other pathogens.
The type D domain (VWFD) is not only presented in the VWF protein but also in many other proteins, such as mucin in the digestive tract (Bukreyeva et al., 2017). Considering the facts that the initial infection site for E. hellem may in the digestive tract, it would be important to investigate the interactions between E. hellem with those VWD domain containing proteins. In addition, vertical/transovarial transmission is a known feature of microsporidia, especially in invertebrates (Dunn et al., 2001). It has been shown that the VWD D'D3like domain-containing protein vitellogenin has an essential role in vertical transmission and involves direct binding of pathogens at this domain (Raina et al., 1995; Herren et al., 2013). Thus, it is important to investigate whether VWF facilitates human infecting-microsporidia, such as E. hellem, to mediate transovarial transmission or assist in pathogen transmission via blood contamination during birthing (Kaneda et al., 1997; Murakami et al., 2012).

In conclusion, the present study revealed that VWF can directly bind the microsporidia E. hellem, at least in part, via its 
A
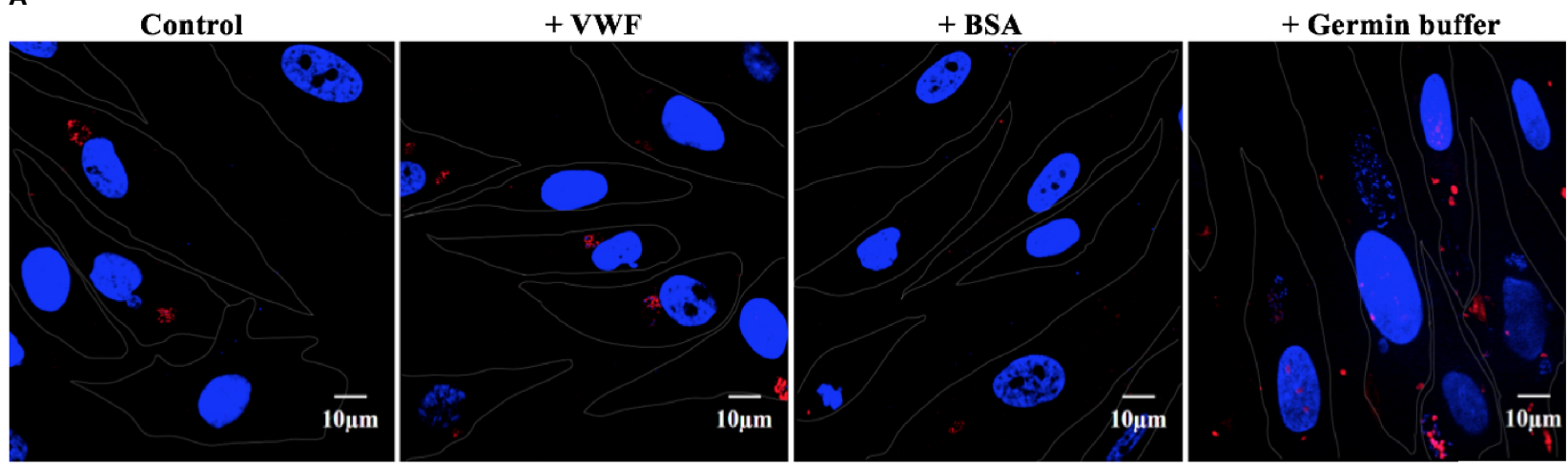

B

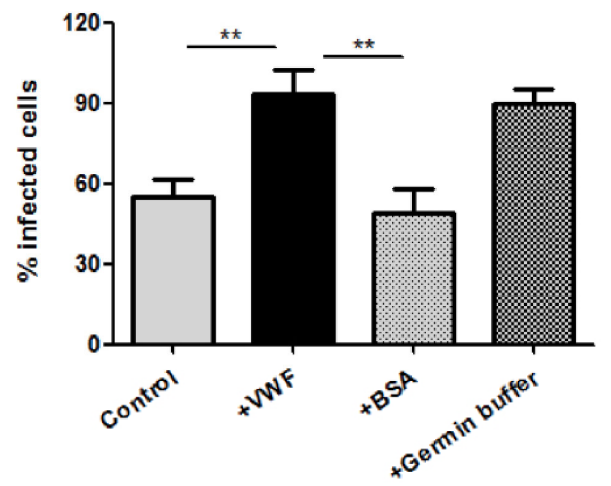

FIGURE 5 | WWF promotes E. hellem infection. (A) Representative fields of HFF cells exposed to E. hellem spores that had undergone no treatment (control) or binding of either FL-WWF or BSA or exposed to germination buffer. The spores were then added to HFF cells and culture for $12 \mathrm{~h}$. The HFF cells outlines were depicted as 'dots' by Adobe Illustrator CS6to the DIC images of the cells. HFF cell nuclei were stained by DAPI (blue), while the infected E. hellem was represented by FISH probe (red) (Scale bar $=10 \mu \mathrm{m}$ ). (B) Infectivity rate was the ratio of infected HFF cells over all cells, based on three independent studies with 20 random fields per study. The result showed that WWF treatment significantly increased the infection rate of $E$. hellem to host cells $\left(F(1,59)=2.42,{ }^{* *}=P<0.01\right)$; while the un-related protein treatment of $E$. hellem spores had no effect on the infection ability $\left(F(1,59)=1.92,{ }^{\star \star} P<0.01\right)$.

VWD domain. This interaction altered multiple biological aspects of the pathogen that eventually lead to enhanced germination and infectivity. These effects make VWF a candidate for being a key mediator of microsporidia intravascular dissemination, and provide insights into the mechanism(s) by which microsporidia can lead to endocarditis, thrombocytopenia and other systemic manifestations. There have no specific therapeutics for

TABLE 1 | Representatives of ddifferentially expressed proteins of $E$. hellem after WWF incubation.

\begin{tabular}{|c|c|c|c|c|}
\hline UniProtKB ID & Protein Name & Unique Peptides & Coverage & Up/Down-regulated \\
\hline I6UNU1 & Glucose-6-phosphate isomerase & 55 & 69.8 & Up \\
\hline I6ULI4 & $40 S$ ribosomal protein S6 & 14 & 38.2 & Up \\
\hline I6TLD3 & Protein YOP1 & 10 & 33.5 & Up \\
\hline Q5VDH6 & Aminopeptidase & 2 & 52.7 & Up \\
\hline I6UEB3 & HTH_9 domain containing protein & 2 & 4.8 & Up \\
\hline I6TI03 & Trehalase & 19 & 31.2 & Down \\
\hline IEUNAO & Ribosomal protein L14E/L6E/L27E & 10 & 54.7 & Down \\
\hline I6TWX8 & V-type proton ATPase subunit a & 8 & 12.1 & Down \\
\hline I6UP05 & Translation initiation factor 2B subunit epsilon & 3 & 6.3 & Down \\
\hline I6UM86 & DNA polymerase sigma & 1 & 5.4 & Down \\
\hline
\end{tabular}




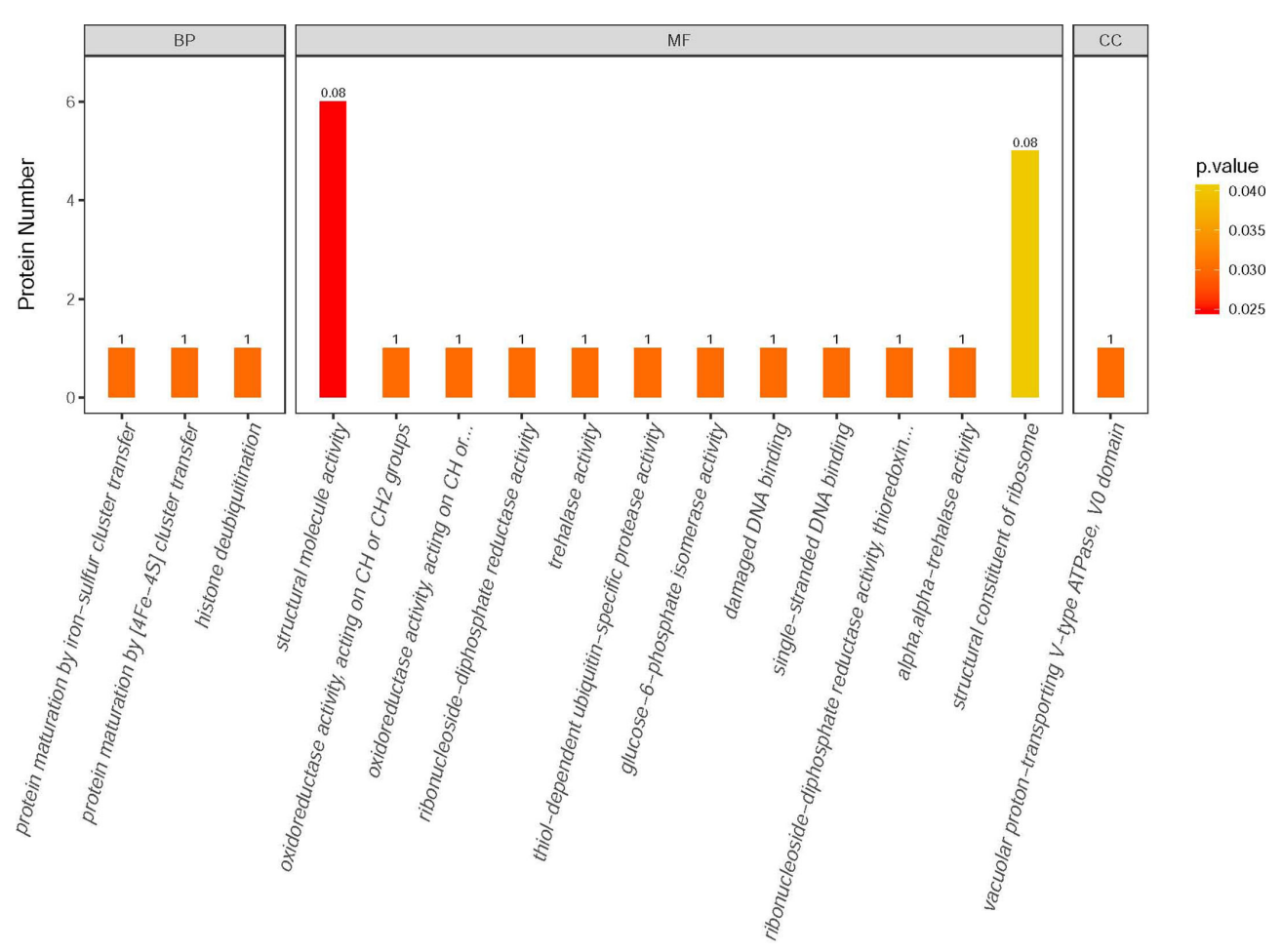

Enriched GO Terms

FIGURE 6 | GO annotation and enrichment analysis of differentially expressed proteins in E. hellem post-exposure to WW. The primary $Y$ axis denotes the number of annotated proteins categorized to each GO term. The secondary $Y$ axis represents the percentage of annotated proteins to each GO term in all differential proteins. GO terms are classified into three subcategories, including biological process (BP), molecular function (MF) and cellular compartment (CC). The color gradient represents the $\mathrm{p}$-value; the closer to red, the smaller the $\mathrm{p}$-value. The enriched proteins are categorized and showed on $\mathrm{X}$ axis as: $1-$ Protein maturation by iron-sulfur cluster transfer; 2-Protein maturation by [4Fe-4S] cluster transfer; 3-Histone deubiquitination; 4-Structural molecule activity; 5-Oxidoreductase activity; 6-Oxidoreductase activity, acting on $\mathrm{CH} 2$ groups; 7 -Ribonucleoside-diphosphate reductase activity; 8-Trehalase activity; 9-Thiol-dependent ubiquitinspecific protease activity; 10-Glucose-6-phosphate isomerise activity; 11-Damage DNA binding; 12-Single-stranded DNA binding; 13-Thioredoxin activity; 14Alpha trehalase activity; 15-Structural constituent of ribosome; 16-Vacuolar proton-transporting V-type ATPase.

microsporidia. Drugs such as albendazole and fumagillin are either non-specific, not able to eliminate the pathogen, and have toxic side-effects (Didier et al., 2005). Thus, novel treatment strategies for microsporidia are necessary. Based on our findings, preventing the binding of microsporidia to VWF, probably via specific antibody neutralizing the binding site, may be an attractive target to prevent microsporidia dissemination and systemic infections.

\section{DATA AVAILABILITY STATEMENT}

The raw data supporting the conclusions of this article will be made available by the authors, without undue reservation.

\section{AUTHOR CONTRIBUTIONS}

JB designed the study and conducted most the experiments, interpreted the data, and wrote the manuscript. BM, GA, JL, TL and GP assisted in germination and infection experiments and analysis of data. MP contributed to study design and with ZZ contributed in manuscript grammar and language editing. All authors contributed to the article and approved the submitted version.

\section{FUNDING}

This work is supported by Fundamental Research Funds for the Central Universities (No. XDJK2020B005) and The National Natural Science Foundation of China (No. 31802141).

\section{ACKNOWLEDGMENTS}

We thank Prof. Louis Weiss for providing E. hellem; Prof Bing Han for HFF cells. We also appreciate Dr. Timothy Keiffer, Postdoctoral Fellow at Georgia State University, as well as Dr. S. Gaylen Bradley, emeritus dean of Basic Health Sciences, Virginia Commonwealth University, for their contributions in correcting the language in this manuscript. 


\section{REFERENCES}

Anderson, N. W., Muehlenbachs, A., Arif, S., Bruminhent, J., Deziel, P. J., Razonable, R. R., et al. (2019). A Fatal Case of Disseminated Microsporidiosis Due to Anncaliia Algerae in a Renal and Pancreas Allograft Recipient. Open Forum Infect. Dis. 6, ofz285. doi: 10.1093/ofid/ofz285

Barber, B. E., William, T., Grigg, M. J., Parameswaran, U., Piera, K. A., Price, R. N., et al. (2015). Parasite Biomass-Related Inflammation, Endothelial Activation, Microvascular Dysfunction and Disease Severity in Vivax Malaria. PloS Pathog. 11, e1004558. doi: 10.1371/journal.ppat.1004558

Bukreyeva, I., Angoulvant, A., Bendib, I., Gagnard, J. C., Bourhis, J. H., Dargere, S., et al. (2017). Enterocytozoon Bieneusi Microsporidiosis in Stem Cell Transplant Recipients Treated With Fumagillin. Emerging Infect. Dis. 23, 1039-1041. doi: 10.3201/eid2306.161825

Delgado Betancourt, E., Hamid, B., Fabian, B. T., Klotz, C., Hartmann, S., and Seeber, F. (2019). From Entry to Early Dissemination-Toxoplasma Gondii's Initial Encounter With Its Host. Front. Cell Infect. Microbiol. 9, 46. doi: $10.3389 /$ fcimb. 2019.00046

Didier, E. S., Maddry, J. A., Brindley, P. J., Stovall, M. E., and Didier, P. J. (2005). Therapeutic Strategies for Human Microsporidia Infections. Expert Rev. Antiinfective Ther. 3, 419-434. doi: 10.1586/14787210.3.3.419

Dong, X., Leksa, N. C., Chhabra, E. S., Arndt, J. W., Lu, Q., Knockenhauer, K. E., et al. (2019). The Von Willebrand Factor D'D3 Assembly and Structural Principles for Factor VIII Binding and Concatemer Biogenesis. Blood 133, 1523-1533. doi: 10.1182/blood-2018-10-876300

Duan, W., Wang, S., Chen, M., Wang, C., Zhang, L., Liu, J., et al. (2006). Harvest Active Recombinant Rho Kinase From Escherichia Coli. Biol. Pharm. Bull. 29, 38-42. doi: 10.1248/bpb.29.38

Dunn, A. M., Terry, R. S., and Smith, J. E. (2001). Transovarial Transmission in the Microsporidia. Adv. Parasitol. 48, 57-100. doi: 10.1016/S0065-308X(01) 48005-5

Franzen, C. (2005). How Do Microsporidia Invade Cells? Folia Parasit 52, 36-40. doi: 10.14411/fp.2005.005

Guirado, E., Schlesinger, L. S., and Kaplan, G. (2013). Macrophages in Tuberculosis: Friend or Foe. Semin. Immunopathol. 35, 563-583. doi: 10.1007/s00281-013-0388-2

Han, B., Moretto, M., and Weiss, L. M. (2019). Encephalitozoon: Tissue Culture, Cryopreservation, and Murine Infection. Curr. Protoc. Microbiol. 52, e72. doi: $10.1002 / \mathrm{cpmc} .72$

Han, B., and Weiss, L. M. (2017). Microsporidia: Obligate Intracellular Pathogens Within the Fungal Kingdom. Microbiol. Spectr. 5 (2), 10. doi: 10.1128/ 9781555819583.ch5

He, Q., Leitch, G. J., Visvesvara, G. S., and Wallace, S. (1996). Effects of Nifedipine, Metronidazole, and Nitric Oxide Donors on Spore Germination and Cell Culture Infection of the Microsporidia Encephalitozoon Hellem and Encephalitozoon Intestinalis. Antimicrobial Agents chemotherapy 40, 179185. doi: 10.1128/AAC.40.1.179

Herren, J. K., Paredes, J. C., Schupfer, F., and Lemaitre, B. (2013). Vertical Transmission of a Drosophila Endosymbiont Via Cooption of the Yolk Transport and Internalization Machinery. mBio 4 (2), e00532-12. doi: 10.1128/mBio.00532-12

Hilbert, L., Jorieux, S., Proulle, V., Favier, R., Goudemand, J., Parquet, A., et al. (2003). Two Novel Mutations, Q1053H and C1060R, Located in the D3 Domain of Von Willebrand Factor, are Responsible for Decreased FVIIIBinding Capacity. Br. J. Haematol. 120, 627-632. doi: 10.1046/j.13652141.2003.04163.x

Hirt, R. P., Logsdon, J.M.,.Jr., Healy, B., Dorey, M. W., Doolittle, W. F., and Embley, T. M. (1999). Microsporidia are Related to Fungi: Evidence From the Largest Subunit of RNA Polymerase II and Other Proteins. Proc. Natl. Acad. Sci. USA 96, 580-585. doi: 10.1073/pnas.96.2.580

Jagau, H., Behrens, I. K., Lahme, K., Lorz, G., Koster, R. W., Schneppenheim, R., et al. (2019). Von Willebrand Factor Mediates Pneumococcal Aggregation and Adhesion in Blood Flow. Front. Microbiol. 10, 511. doi: 10.3389/ fmicb.2019.00511

Kaneda, T., Shiraki, K., Hirano, K., and Nagata, I. (1997). Detection of Maternofetal Transfusion by Placental Alkaline Phosphatase Levels. J. Pediatr. 130, 730-735. doi: 10.1016/S0022-3476(97)80014-5
Kong, Q. F., Lv, B., Wang, B., Zhang, X. P., Sun, H. J., and Liu, J. (2020). Association of Von Willebrand Factor (Vwf) Expression With Lymph Node Metastasis and Hemodynamics in Papillary Thyroid Carcinoma. Eur. Rev. Med. Pharmacol. Sci. 24, 2564-2571. doi: 10.26355/eurrev_202003_20525

Kugler, W., and Lakomek, M. (2000). Glucose-6-Phosphate Isomerase Deficiency. Bailliere's Best Pract. Res. Clin. Haematol. 13, 89-101. doi: 10.1053/ beha.1999.0059

Leitch, G. J., He, Q., Wallace, S., and Visvesvara, G. S. (1993). Inhibition of the Spore Polar Filament Extrusion of the Microsporidium, Encephalitozoon Hellem, Isolated From an AIDS Patient. J. Eukaryot. Microbiol. 40, 711-717. doi: 10.1111/j.1550-7408.1993.tb04463.x

Lenting, P. J., Christophe, O. D., and Denis, C. V. (2015). Von Willebrand Factor Biosynthesis, Secretion, and Clearance: Connecting the Far Ends. Blood 125, 2019-2028. doi: 10.1182/blood-2014-06-528406

Lu, W., Lu, C., Zhang, Q., Cao, S., Zhang, Z., Jia, H., et al. (2020). Localization and Enzyme Kinetics of Aminopeptidase N3 From Toxoplasma Gondii. Parasitol. Res. 119, 357-364. doi: 10.1007/s00436-019-06512-6

Luna, V. A., Stewart, B. K., Bergeron, D. L., Clausen, C. R., Plorde, J. J., and Fritsche, T. R. (1995). Use of the Fluorochrome Calcofluor White in the Screening of Stool Specimens for Spores of Microsporidia. Am. J. Clin. Pathol. 103, 656-659. doi: 10.1093/ajcp/103.5.656

Madabhushi, S. R., Zhang, C., Kelkar, A., Dayananda, K. M., and Neelamegham, S. (2014). Platelet Gpiba Binding to Von Willebrand Factor Under Fluid Shear: Contributions of the D'D3-Domain, A1-Domain Flanking Peptide and OLinked Glycans. J. Am. Heart Assoc. 3, e001420. doi: 10.1161/JAHA. 114.001420

Meissner, E. G., Bennett, J. E., Qvarnstrom, Y., da Silva, A., Chu, E. Y., Tsokos, M., et al. (2012). Disseminated Microsporidiosis in an Immunosuppressed Patient. Emerging Infect. Dis. 18, 1155-1158. doi: 10.3201/eid1807.120047

Meng, X. Z., Luo, B., Tang, X. Y., He, Q., Xiong, T. R., Fang, Z. Y., et al. (2018). Pathological Analysis of Silkworm Infected by Two Microsporidia Nosema Bombycis CQ1 and Vairimorpha Necatrix BM. J. Invertebr. Pathol. 153, 75-84. doi: 10.1016/j.jip.2017.12.005

Michaux, G., Pullen, T. J., Haberichter, S. L., and Cutler, D. F. (2006). P-Selectin Binds to the D '-D3 Domains of Von Willebrand Factor in Weibel-Palade Bodies. Blood 107, 3922-3924. doi: 10.1182/blood-2005-09-3635

Murakami, J., Nagata, I., Iitsuka, T., Okamoto, M., Kaji, S., Hoshika, T., et al. (2012). Risk Factors for Mother-to-Child Transmission of Hepatitis C Virus: Maternal High Viral Load and Fetal Exposure in the Birth Canal. Hepatology Res. Off. J. Japan Soc. Hepatology 42, 648-657. doi: 10.1111/j.1872034X.2012.00968.x

O'Seaghdha, M., van Schooten, C. J., Kerrigan, S. W., Emsley, J., Silverman, G. J., Cox, D., et al. (2006). Staphylococcus Aureus Protein a Binding to Von Willebrand Factor A1 Domain is Mediated by Conserved Igg Binding Regions. FEBS J. 273, 4831-4841. doi: 10.1111/j.1742-4658.2006.05482.x

Pariyakanok, L., Satitpitakul, V., Laksanaphuk, P., Ratanawongphaibul, K., Putaporntip, C., and Jongwutiwes, S. (2019). Stromal Keratitis With Endophthalmitis Caused by Vittaforma Corneae in an Immunocompetent Patient: A Case Report. Ocul. Immunol. Inflamm. 27, 826-828. doi: 10.1080/ 09273948.2018.1455875

Park, G. S., Ireland, K. F., Opoka, R. O., and John, C. C. (2012). Evidence of Endothelial Activation in Asymptomatic Plasmodium Falciparum Parasitemia and Effect of Blood Group on Levels of Von Willebrand Factor in Malaria. J. Pediatr. Infect. Dis. Soc. 1, 16-25. doi: 10.1093/jpids/pis010

Pattana Jaroenlak, M. C., Davydov, A., Sall, J., Usmani, M., Liang, F.-X., Ekiert, D. C., et al. (2020). 3-Dimensional Organization and Dynamics of the Microsporidian Polar Tube Invasion Machinery. bioRxiv 2020, 04.03.024240. doi: 10.1371/ journal.ppat.1008738

Pillai, V. G., Bao, J., Zander, C. B., McDaniel, J. K., Chetty, P. S., Seeholzer, S. H., et al. (2016). Human Neutrophil Peptides Inhibit Cleavage of Von Willebrand Factor by ADAMTS13: A Potential Link of Inflammation to TTP. Blood 128, 110-119. doi: 10.1182/blood-2015-12-688747

Raina, S. K., Das, S., Rai, M. M., and Khurad, A. M. (1995). Transovarial Transmission of Nosema Locustae (Microsporida: Nosematidae) in the Migratory Locust Locusta Migratoria Migratorioides. Parasitol. Res. 81, 38 44. doi: 10.1007/BF00932415

Robertson, P. D., Warren, E. M., Zhang, H., Friedman, D. B., Lary, J. W., Cole, J. L., et al. (2008). Domain Architecture and Biochemical Characterization of 
Vertebrate Mcm10. J. Biol. Chem. 283, 3338-3348. doi: 10.1074/ jbc.M706267200

Sadler, J. E. (1998). Biochemistry and Genetics of Von Willebrand Factor. Annu. Rev. Biochem. 67, 395-424. doi: 10.1146/annurev.biochem.67.1.395

Shapiro, S. E., Nowak, A. A., Wooding, C., Birdsey, G., Laffan, M. A., and McKinnon, T. A. (2014). The Von Willebrand Factor Predicted Unpaired Cysteines are Essential for Secretion. J. Thromb. haemostasis JTH 12, 246-254. doi: $10.1111 /$ jth.12466

Shiltagh, N., Kirkpatrick, J., Cabrita, L. D., McKinnon, T. A., Thalassinos, K., Tuddenham, E. G., et al. (2014). Solution Structure of the Major Factor VIII Binding Region on Von Willebrand Factor. Blood 123, 4143-4151. doi: 10.1182/blood-2013-07-517086

Sicard, J. F., Le Bihan, G., Vogeleer, P., Jacques, M., and Harel, J. (2017). Interactions of Intestinal Bacteria With Components of the Intestinal Mucus. Front. Cell Infect. Microbiol. 7, 387. doi: 10.3389/fcimb.2017.00387

Small, H. J., Meyer, G. R., Stentiford, G. D., Dunham, J. S., Bateman, K., and Shields, J. D. (2014). Ameson Metacarcini Sp. Nov. (Microsporidia) Infecting the Muscles of Dungeness Crabs Metacarcinus Magister From British Columbia, Canada. Dis. Aquat. Org. 110, 213-225. doi: 10.3354/dao02754

Steinert, M., Ramming, I., and Bergmann, S. (2020). Impact of Von Willebrand Factor on Bacterial Pathogenesis. Front. Med. 7, 543. doi: 10.3389/ fmed.2020.00543

Ueda, Y., Mohammed, I., Song, D., Gullipalli, D., Zhou, L., Sato, S., et al. (2017). Murine Systemic Thrombophilia and Hemolytic Uremic Syndrome From a Factor H Point Mutation. Blood 129, 1184-1196. doi: 10.1182/blood-2016-07728253

Valencakova, A., and Danisova, O. (2019). Molecular Characterization of New Genotypes Enterocytozoon Bieneusi in Slovakia. Acta Trop. 191, 217-220. doi: 10.1016/j.actatropica.2018.12.031

van den Dries, L. W. J., Gruters, R. A., Hovels-van der Borden, S. B. C., Kruip, M. J. H. A., de Maat, M. P. M., van Gorp, E. C. M., et al. (2015). Von Willebrand Factor is Elevated in HIV Patients With a History of Thrombosis. Front. Microbiol. 6, 190. doi: 10.3389/fmicb.2015.00180

Vergauwe, R. M., Uji-i, H., De Ceunynck, K., Vermant, J., Vanhoorelbeke, K., and Hofkens, J. (2014). Shear-Stress-Induced Conformational Changes of Von Willebrand Factor in a Water-Glycerol Mixture Observed With Single Molecule Microscopy. J. Phys. Chem. B 118, 5660-5669. doi: 10.1021/jp5022664

Viela, F., Prystopiuk, V., Leprince, A., Mahillon, J., Speziale, P., Pietrocola, G., et al. (2019). Binding of Staphylococcus Aureus Protein a to Von Willebrand Factor is Regulated by Mechanical Force. mBio 10 (2), e00555-19. doi: 10.1128/ mBio.00555-19

Viljanen, J., Lounatmaa, K., and Makela, P. H. (1991). Expression of the Virulence Plasmid-Determined Protein YOP1 and Hela Cell Invasiveness of Yersinia Enterocolitica O:3. Contributions to Microbiol. Immunol. 12, 176-181.
Visvesvara, G. S., Leitch, G. J., Moura, H., Wallace, S., Weber, R., and Bryan, R. T. (1991). Culture, Electron Microscopy, and Immunoblot Studies on a Microsporidian Parasite Isolated From the Urine of a Patient With AIDS. J. Protozoology 38, 105S-111S.

Volonte, F., Piubelli, L., and Pollegioni, L. (2011). Optimizing HIV-1 Protease Production in Escherichia Coli as Fusion Protein. Microb. Cell Fact 10, 53. doi: 10.1186/1475-2859-10-53

Weber, R., Bryan, R. T., Schwartz, D. A., and Owen, R. L. (1994). Human Microsporidial Infections. Clin. Microbiol. Rev. 7, 426-461. doi: 10.1128/ CMR.7.4.426

Weber, R., Kuster, H., Visvesvara, G. S., Bryan, R. T., Schwartz, D. A., and Luthy, R. (1993). Disseminated Microsporidiosis Due to Encephalitozoon Hellem: Pulmonary Colonization, Microhematuria, and Mild Conjunctivitis in a Patient With AIDS. Clin. Infect. Dis. an Off. Publ. Infect. Dis. Soc. America 17, 415-419. doi: 10.1093/clinids/17.3.415

Weiss, L. M. (1995). and Now Microsporidiosis. Ann. Internal Med. 123, 954-956. doi: 10.7326/0003-4819-123-12-199512150-00012

Weiss, L. M. (2001). Microsporidia: Emerging Pathogenic Protists. Acta Trop. 78, 89-102. doi: 10.1016/S0001-706X(00)00178-9

Yazar, S., Eser, B., Yalcin, S., Sahin, I., and Koc, A. N. (2003). A Case of Pulmonary Microsporidiasis in an Acute Myeloblastic Leukemia (AML) - M3 Patient. Yonsei Med. J. 44, 146-149. doi: 10.3349/ymj.2003.44.1.146

Yee, A., Gildersleeve, R. D., Gu, S., Kretz, C. A., McGee, B. M., Carr, K. M., et al. (2014). A Von Willebrand Factor Fragment Containing the D'D3 Domains is Sufficient to Stabilize Coagulation Factor VIII in Mice. Blood 124, 445-452. doi: 10.1182/blood-2013-11-540534

Zhao, L., Yang, M., Shen, Q., Liu, X., Shi, Z., Wang, S., et al. (2016). Functional Characterization of Three Trehalase Genes Regulating the Chitin Metabolism Pathway in Rice Brown Planthopper Using RNA Interference. Sci. Rep. 6, 27841. doi: $10.1038 /$ srep27841

Zheng, X. L., and Sadler, J. E. (2008). Pathogenesis of Thrombotic Microangiopathies. Annu. Rev. Pathol. 3, 249-277. doi: 10.1146/annurev. pathmechdis.3.121806.154311

Conflict of Interest: The authors declare that the research was conducted in the absence of any commercial or financial relationships that could be construed as a potential conflict of interest.

Copyright $\odot 2021$ Bao, Mo, An, Luo, Poncz, Pan, Li and Zhou. This is an open-access article distributed under the terms of the Creative Commons Attribution License (CC BY). The use, distribution or reproduction in other forums is permitted, provided the original author(s) and the copyright owner(s) are credited and that the original publication in this journal is cited, in accordance with accepted academic practice. No use, distribution or reproduction is permitted which does not comply with these terms. 